\title{
Solanum paranense Extracts and Solanine Present Anti-Inflammatory Activity in an Acute Skin Inflammation Model in Mice
}

\author{
Mariana Piana, ${ }^{1}$ Camila Camponogara, ${ }^{2}$ \\ Aline Augusti Boligon, ${ }^{1}$ and Sara Marchesan Oliveira ${ }^{2}$ \\ ${ }^{1}$ Laboratório de Análises Fitoquímicas, Programa de Pós-Graduação em Ciências Farmacêuticas, \\ Universidade Federal de Santa Maria, 97.105-900 Santa Maria, RS, Brazil \\ ${ }^{2}$ Laboratório de Neurotoxicidade e Psicofarmacologia, Programa de Pós-Graduação em Ciências Biológicas: \\ Bioquímica Toxicológica, Universidade Federal de Santa Maria, 97.105-900 Santa Maria, RS, Brazil
}

Correspondence should be addressed to Sara Marchesan Oliveira; saramarchesan@hotmail.com

Received 17 January 2017; Revised 3 April 2017; Accepted 20 April 2017; Published 24 May 2017

Academic Editor: Jairo Kennup Bastos

Copyright (C) 2017 Mariana Piana et al. This is an open access article distributed under the Creative Commons Attribution License, which permits unrestricted use, distribution, and reproduction in any medium, provided the original work is properly cited.

The aim of the study was to evaluate the anti-inflammatory activity of the $S$. paranense crude extract, $S$. paranense alkaloid fraction, and solanine alkaloid. These samples reduce the croton oil-induced ear edema in a dose-dependent manner and a maximum inhibition of $81 \%, 98 \%$, and $80 \%$ in the doses of $1.0,0.73$, and $0.37 \mathrm{mg} /$ ear, respectively. Moreover, the samples inhibit the MPO activity with an inhibition maximum of $51 \%, 40 \%$, and $46 \%$ in the doses of $1.0,0.73$, and $0.37 \mathrm{mg} / \mathrm{ear}$, respectively. Similar results were found for dexamethasone $0.10 \mathrm{mg} /$ ear (positive control), which showed inhibitions of ear edema and MPO activity of $100 \%$ and $65 \%$, respectively. These results found probably are related to the presence of solanine which is present in significant quantity in the alkaloid fraction and others as rutin and rosmarinic, chlorogenic, and gallic acids. These results support the use of $S$. paranense for the treatment of inflammatory skin disorders.

\section{Introduction}

The skin is the first interface between the body and the environment, providing the primary defense against microbial pathogens and injuries through physical, biochemical, and immunological mechanisms [1]. The regulation of these mechanisms is essential because they are implicated in the pathogenesis of several topical inflammatory disorders [2].

In the inflammatory process, the high levels of inflammatory cytokines and reactive oxygen species are produced and maintained by an interaction of various inflammatory cells that migrates to the inflammation site in response to the release of proinflammatory mediators [2]. This way, the extracts represent potential for the treatment of topical inflammatory diseases because substances from plants, such as phenolic acids, alkaloids, flavonoids, terpenes, and catechins, are known to modulate the expression of proinflammatory signals due to the capacity to inhibiting enzymes and proinflammatory mediators [3].

Several studies showed that Solanum species has antiinflammatory activity, like Solanum corymbiflorum [4] in an acute skin inflammation model, Solanum lycopersicum [5] and Solanum trilobatum [6] in a carrageenan-induced paw edema rat model, and Solanum nigrum [7] in a subacute granuloma inflammation model. However, many species of this genus have no research about its anti-inflammatory activity. Solanum paranense Dusén is among such species, popularly known as Joá-velame, belonging to genus Solanum (family Solanum) [8], and until the moment, there are no studies related to this species. Taking into consideration these facts, the aim of this study was to evaluate the topical antiinflammatory activity of the $S$. paranense crude extract, $S$. paranense alkaloid fraction, and the solanine alkaloid on an 
acute model of skin inflammation in mice and relate this activity with its constituent compounds.

\section{Material and Methods}

2.1. Drugs. The following drugs were used to execute the experimental protocols: Croton oil, hexadecyltrimethylammonium bromide (HTAB), tetramethylbenzidine (TMB), dexamethasone, rutin, gallic acid, ascorbic acid, chlorogenic acid, rosmarinic acid, solanine, DPPH, ammonium phosphate monobasic (all from Sigma, St. Louis, MO, USA), hematoxylin-eosin, acetonitrile, butanol, paraffin, ethanol, and Folin-Ciocalteu (all from Merck, Whitehouse Station, New Jersey, USA), Isoflurane (Baxter, São Paulo, Brazil), sodium acetate, acetone, acetic acid, and formaldehyde (all from Vetec, Rio de Janeiro, Brazil).

2.2. Plant Collection and Extractions. Leaves of S. paranense were collected in Gaurama (Rio Grande do Sul State of Brazil) in February (2013). A dried voucher specimen is preserved in the herbarium of the Department of Biology at Federal University of Santa Maria (register number, SMBD 13748). The leaves ( $500 \mathrm{~g}$ ) were dried and powdered in a knife mill; this material was macerated at room temperature with $70 \%$ ethanol for a week, with daily shake-up. After filtration, the hydroalcoholic extract was evaporated under reduced pressure to remove the ethanol; this was taken to complete dryness in stove (temperature below $40^{\circ} \mathrm{C}$ ), yielding the extract.

The quantity of $1.50 \mathrm{~g}$ of extract was used to get the alkaloid fraction, according to the method described by Sotelo and Serrano [9], with modifications.

\subsection{Phytochemical Compounds}

2.3.1. HPLC Analysis of Phenolic Compounds on S. paranense Extract. The phenolic compounds analysis was performed by high performance liquid chromatography (HPLC), through the method described by Zadra et al. [10], slightly modified in a Shimadzu Prominence system (Kyoto, Japan) equipped with a SIL-20A autosampler, equipped with Shimadzu LC20 at reciprocating pumps connected to the degasser DGU 20A5 with integrator CBM 20A, UV-VIS detector DAD SPDM20A, and Software LC Solution 1.22 SP1. Reverse phase chromatographic analyses were carried out under gradient conditions, using a C-18 column $(4.6 \mathrm{~mm} \times 250 \mathrm{~mm})$ packed with $5 \mathrm{~mm}$ diameter particles; the mobile phase 1 was acetic acid $2.0 \%$ in water and mobile phase 2 was methanol. All solutions, mobile phase, and samples were firstly dissolved in the mobile phase and filtered through a $0.45 \mathrm{~mm}$ membrane filter (Millipore). The chromatographic peaks were confirmed by comparing their retention time and Diode-Array-UV spectra with those of the reference standards chlorogenic acid $(327 \mathrm{~nm})$, gallic acid $(272 \mathrm{~nm})$, rosmarinic acid $(330 \mathrm{~nm})$, and rutin $(355 \mathrm{~nm})$. The flow rate was $0.6 \mathrm{~mL} / \mathrm{min}$, and the injection volume was $40 \mu \mathrm{l}$. All chromatographic operations were carried out at room temperature and in triplicate.
2.3.2. HPLC Analysis of Solanine on S. paranense Alkaloid Fraction. HPLC analysis of solanine was carried out according to Sotelo and Serrano [9] in the same equipment described previously. Reverse phase chromatographic analysis was carried out under isocratic conditions, using a C-18 column $(4.6 \mathrm{~mm} \times 150 \mathrm{~mm})$ packed with $5 \mathrm{~mm}$ diameter particles. The mobile phase was acetonitrile $-0.05 \mathrm{M}$ monobasic ammonium phosphate buffer $(3: 7, \mathrm{v} / \mathrm{v})$, at $\mathrm{pH} 6.5$. The solvent flow was $1.2 \mathrm{~mL} / \mathrm{min}$ and an injection volume $20 \mu \mathrm{L}$. The quantification was performed using the method of the internal standard. The chromatographic peaks were confirmed by comparing their retention time and Diode-ArrayUV spectra with reference standard solanine at $200 \mathrm{~nm}$. All chromatographic operations were carried out at room temperature and in triplicate.

2.4. Animals. Male adult Swiss mice (25-30 g) were used in the experiments. The animals were provided by the Central Biotery of the Federal University of Santa Maria. After the acquisition, they were divided into groups and kept in a temperature-controlled room $\left(22 \pm 2^{\circ} \mathrm{C}\right)$ under a $12 \mathrm{~h}$ lightdark cycle. Animals were acclimatized to the laboratory for at least $1 \mathrm{~h}$ before the experiments and were used only once. All of the experiments were carried out between 8:00 a.m. and 5:00 p.m. The data reported in this study were carried out in accordance with national and international legislation (guidelines of Brazilian Council of Animal Experimentation, CONCEA, and U.S. Public Health Service's Policy on Humane Care and Use of Laboratory Animals, PHS Policy) and with the approval of the Ethics Committee for Animal Research of the Federal University of Santa Maria (process $6481091215 / 2016$ ). The animals were separated into 6 groups in each experiment with 6 animals by the group, totaling a final number of 150 animals. The number of animals and the amount of irritant agent were the minimum necessary to demonstrate the consistent effects of the drug treatments.

2.5. Inflammatory Parameters Measurements. Skin inflammation was induced by topical application of croton oil, and the inflammatory response was assessed through edema formation, infiltration of inflammatory cells (myeloperoxidase activity), and histological procedure.

2.6. Treatments. The $S$. paranense crude extract $(0.01-1 \mathrm{mg} /$ ear), S. paranense alkaloid fraction (0.01-0.73 mg/ear), solanine (0.001-0.37 mg/ear), or dexamethasone $(0.1 \mathrm{mg} /$ ear; used as a positive control) was dissolved in $20 \mu \mathrm{L}$ of acetone and applied topically before the croton oil treatment. The animals ear thickness was measured before and after the application of the irritant agent [4]. Six hours after the treatment with croton oil, the animals were sacrificed, and ear samples (circles of tissue $6 \mathrm{~mm}$ in diameter) were collected for further analysis.

2.7. Croton Oil-Induced Ear Edema. The ear edema was induced by a unique topical application of croton oil at a concentration of $1 \mathrm{mg}$ /ear in the right ear of the mice and was manifested as an increase of ear thickness [4]. The $S$. paranense crude extract, alkaloid fraction, solanine, or 


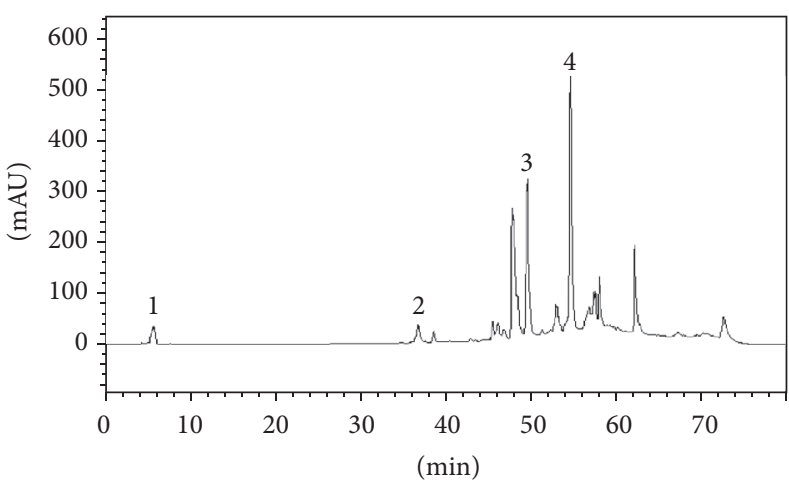

(a)

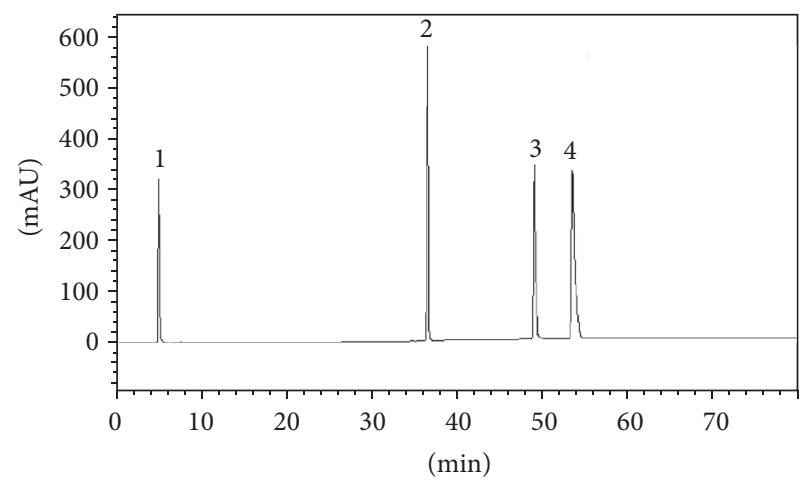

(b)

Figure 1: Chromatogram S. paranense extract (a) and the chromatogram of standards (b). 1 corresponds to gallic acid peak, 2 chlorogenic acid, 3 rosmarinic acid, and 4 rutin.

dexamethasone was applied topically immediately before the croton oil treatment. The thickness was measured before and after induction of the inflammatory response using a digital micrometer (Digimess) in animals anesthetized with isoflurane [11]. The micrometer was applied near the tip of the ear just distal to the cartilaginous ridges. The thickness was represented by the variation before and $6 \mathrm{~h}$ after treatment and expressed in $\mu \mathrm{m}$. To minimize variation, a single investigator performed the measurements throughout each experiment.

2.8. Myeloperoxidase Activity (MPO) Assay. The myeloperoxidase activity is used as a biochemical marker of polymorphonuclear leukocyte influx (mainly neutrophil) to the injured tissue. MPO activity was determined using an assay described previously [11, 12]. After six hours of application of croton oil, the MPO enzyme activity was assessed in the ear samples. Tissue samples were homogenized with a motor-driven homogenizer in acetate buffer $(8 \mathrm{mM}, \mathrm{pH} 5.4)$ containing HTAB. For evaluation of MPO activity, the supernatant was incubated with TMB $(18.4 \mathrm{mM})$ at $37^{\circ} \mathrm{C}$ for $3 \mathrm{~min}$. The enzyme activity value was assessed colorimetrically at $630 \mathrm{~nm}$ using a microplate reader (Fisher Biotech BT, 2000). The results were expressed as optical density $(\mathrm{OD}) / \mathrm{mL}$ of the sample.

2.9. Histological Assessment of Skin Tissue. To verify the histological changes in the mice ear after irritant agent and treatments application, samples were collected six hours after the induction of inflammation. Mice were euthanized, and ear tissue was removed and fixed in alfac solution (a 16:2:1 mixture of ethanol $80 \%$, formaldehyde $40 \%$, and acetic acid). The ears were subsequently embedded in paraffin, sectioned to $5 \mathrm{~mm}$, and stained with hematoxylin-eosin. The leukocytes infiltration was assessed in representative areas selected with 20x and 40x increments. The quantification of leukocytes in the tissue (dermis) was performed by counting the cells per field, and five fields from three distinct histological sections of each group were analyzed. To minimize a source of bias, the investigator analyzed the specimens blindly [4].
2.10. Statistical Analysis. The results are presented as mean \pm SEM with exception of the $\mathrm{ID}_{50}$ values (dose required to reduce the responses of the treated groups by $50 \%$ relative to the control group), which are reported as geometric means plus their respective 95\% confidence limits. The maximum inhibitory effect $\left(E_{\max }\right)$ was calculated based on the response of the control groups. The statistical significance between the groups was assessed by one-way analysis of variance (ANOVA) followed by a post hoc Newman-Keuls test. For phenolic composition calibration curves were used; the experimental values were expressed as mean $\pm \operatorname{SEM}(n=3)$. For solanine mean $\pm \operatorname{SEM}(n=3)$ was used. All tests were carried out using GraphPad 5.0 Software (San Diego, CA, USA). The accepted level of significance for the test was $P<$ 0.05 .

\section{Results}

3.1. Phytochemical Analysis. The yield of the extract was $8.83 \%(\mathrm{w} / \mathrm{w})$. In the analysis by HPLC, it was possible to quantify gallic acid $(6.41 \pm 0.15 \mathrm{mg} / \mathrm{g})$, chlorogenic acid ( $5.74 \pm$ $1.00 \mathrm{mg} / \mathrm{g})$, rosmarinic acid $(9.43 \pm 0.29 \mathrm{mg} / \mathrm{g})$, and rutin $(21.85 \pm 0.45 \mathrm{mg} / \mathrm{g})$ (Figure 1).

The alkaloid fraction showed a yield of $73 \%(\mathrm{w} / \mathrm{w})$ in relation to the extract and analysis by HPLC $506 \pm 1.75 \mathrm{mg} / \mathrm{g}$ of solanine in the $S$. paranense alkaloid fraction and consequently $371.06 \mathrm{mg} / \mathrm{g}$ in the crude extract (Figure 2) were quantified.

3.2. Croton Oil-Induced Inflammatory Parameters. We assessed the anti-inflammatory activity of the crude extract, alkaloid fraction of $S$. paranense, and solanine in a croton oil-induced acute skin inflammation model. A single topical application of croton oil on the ear induced a marked increase in the ear thickness, with $E_{\max }$ of $142 \pm 8 \mu \mathrm{m}$ when evaluated $6 \mathrm{~h}$ after the induction of inflammation process. On the other hand, the topical application of vehicle (acetone) alone did not significantly change the ear thickness $(0.023 \pm 0.04 \mu \mathrm{m})$ (Figure 3(a)). This parameter is indicative of some processes that occur during skin inflammation, including increased 


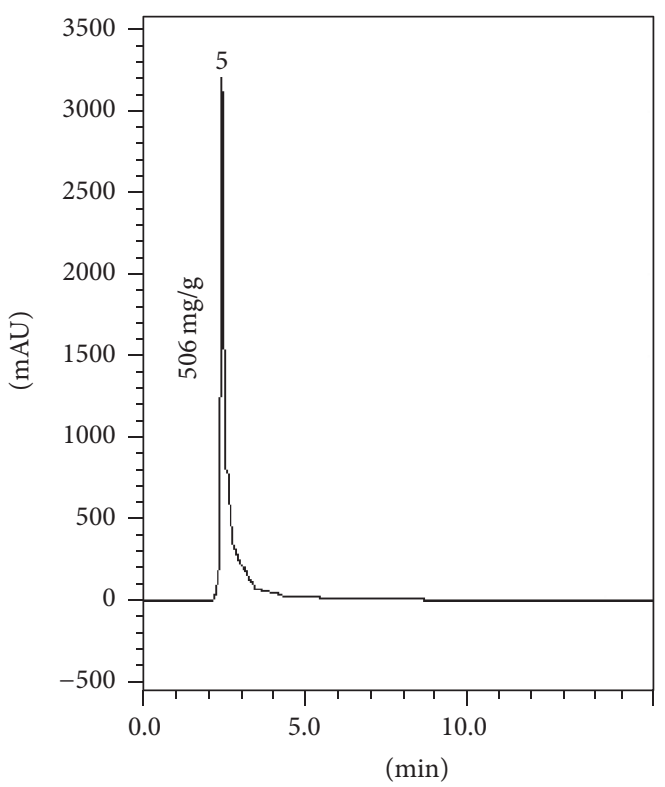

FIGURE 2: Chromatogram of $S$. paranense alkaloid fraction. 5 corresponds to solanine.

vascular permeability, edema, and swelling within the dermis [13].

The crude extract (0.01-1 mg/ear), alkaloid fraction (0.01-0.73 mg/ear), and solanine (0.001-0.37 mg/ear) topically applied inhibited the croton oil-induced ear edema in a dose-dependent manner, with an $\mathrm{ID}_{50}$ value of 0.06 (0.03-0.12), 0.08 (0.06-0.11), and 0.004 (0.002-0.009) mg/ear and a maximum inhibition of $81 \pm 7 \%$ (at $1 \mathrm{mg} / \mathrm{ear}$ ), $98 \pm 1 \%$ ( $0.73 \mathrm{mg} /$ ear), and $80 \pm 6 \%$ (0.37 mg/ear), respectively (Figures 3(a), 3(b), and 3(c)). Dexamethasone (positive control) inhibited the croton oil-induced ear edema with maximal inhibition of $100 \%$ (Figure 3).

MPO is a biochemical marker of polymorphonuclear leukocytes and its activity is directly related to the amount of neutrophil infiltration, which is indicative of an inflammatory process. Croton oil caused an increase in the MPO activity when compared with the naive group and the topical application of the crude extract, alkaloid fraction, and solanine was able to inhibit the croton oil-induced increase of MPO enzyme activity with an $\mathrm{ID}_{50}$ value of $0.04(0.007-0.23), 0.05$ (0.02-0.11), and $0.012(0.004-0.036) \mathrm{mg} /$ ear and a maximum inhibition of $51 \pm 4 \%$ ( $1 \mathrm{mg} / \mathrm{ear}), 40 \pm 3 \%$ ( $0.73 \mathrm{mg} / \mathrm{ear})$, and $46 \pm 1 \%$ (0.37 mg/ear), respectively (Figures $4(\mathrm{a}), 4(\mathrm{~b})$, and 4 (c)) while dexamethasone reduced MPO activity in $65 \pm 5 \%$ (Figure 4).

3.3. Histological Assessment of Ear Tissue. Once we observed the development of an inflammatory process after croton oil application, we investigated histological changes in the ear tissue at $6 \mathrm{~h}$ after the application of croton oil or croton oil plus treatments. Histological sections of the mice ears submitted to unique topical application of croton oil (Figure 5(a)) revealed the presence edema characterized by an intense increase of the ear thickness, especially at the dermis and expressive polymorphonuclear leukocytes migration, especially on croton oil group $(172 \pm 22$ polymorphonuclear cells per field; Figure 5(b)), when compared with the naïve $(34 \pm 3$ polymorphonuclear cells per field) or vehicle ( $48 \pm 6$ polymorphonuclear cells per field) group. The topical application of extract ( $1 \mathrm{mg} /$ ear $)$, alkaloid fraction $(0.73 \mathrm{mg} / \mathrm{ear})$, solanine (0.37 $\mathrm{mg} /$ ear), and dexamethasone $(0.1 \mathrm{mg} /$ ear $)$ decreased the edema and inflammatory cells infiltration $(72 \pm 7,58 \pm 7$, $83 \pm 5$, and $63 \pm 3$ polymorphonuclear cells per field, resp.) in comparison to croton oil group (Figures 5(a) and 5(b)).

\section{Discussion}

The scientific and empirical literature relates that several species of genus Solanum present skin antiedematogenic and anti-inflammatory activities $[4,14,15]$. Here, we show, for the first time, the anti-inflammatory activity of the solanine, crude extract, and alkaloid fraction of S. paranense. Solanine, alkaloid fraction, and crude extract of $S$. paranense were capable of reducing the ear edema and the inflammatory cell infiltration, demonstrated by MPO activity and confirmed by histological procedure, in a topical dermatitis model induced by croton oil application, indicating that the antiedematogenic activity is associated with decrease of inflammatory cells infiltration. Similar results were found by another work from our research group [4], which demonstrated that the extract of the genus Solanum leaves, species Solanum corymbiflorum, presents skin anti-inflammatory activity in a dermatitis model induced by croton oil. Moreover, Da Costa et al. [16] also showed that the hydroethanol fraction of the genus Solanum leaves, species Solanum lycocarpum, presents antiedematogenic activity in a carrageenan-induced paw edema model. 


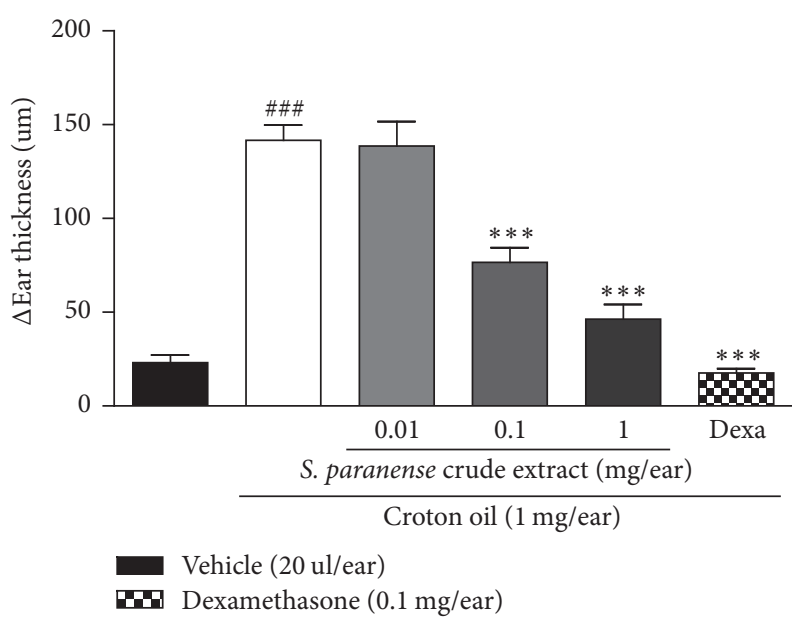

(a)

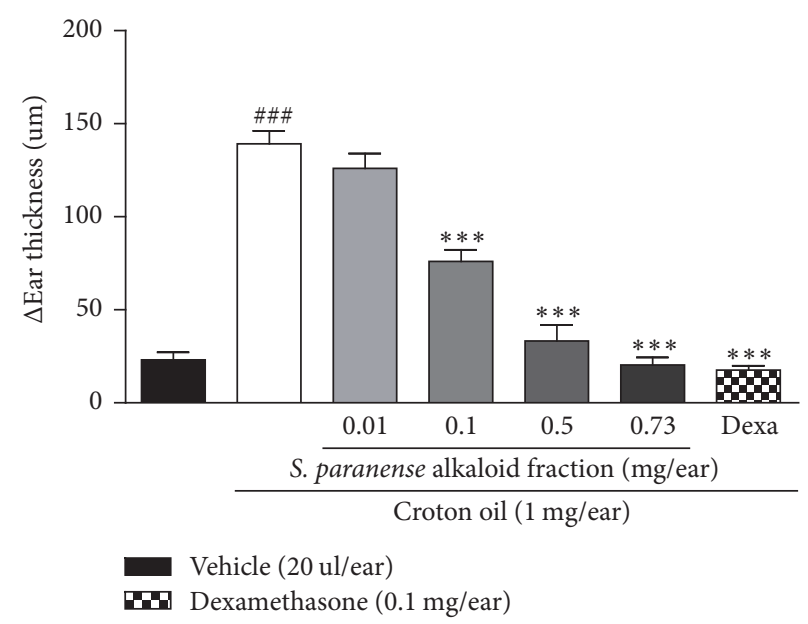

(b)

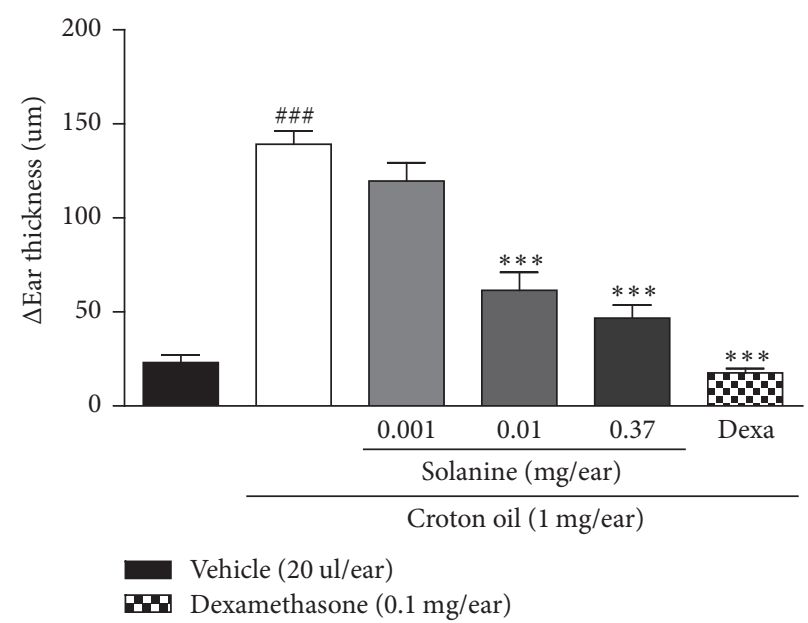

(c)

FIGURE 3: Effect of the S. paranense crude extract (a), S. paranense alkaloid fraction (b), solanine (c), and dexamethasone (Dexa) administered topically on croton oil-induced acute ear edema. Each bar represents the mean $+\operatorname{SEM}(n=6) ;{ }^{\# \# \#} P<0.001$ when compared with the vehicle (acetone) group. ${ }^{* * *} P<0.001$ when compared with the croton oil group (one-way ANOVA followed by post hoc Newman-Keuls test).

We demonstrated which $S$. Paranense extract has important polyphenols already found in other extracts of the genus Solanum and other genuses with described antiinflammatory activity $[17,18]$. Among the compounds with an anti-inflammatory activity, we highlight the rutin (21.85 $\mathrm{mg} / \mathrm{g}$ ) and rosmarinic acid (9.43). Rutin is a constituent found in large quantities in the Viola tricolor flowers which present anti-inflammatory effect in a burn model [17]. Rosmarinic acid showed an anti-inflammatory effect on ear edema and other models of inflammation through inhibition of adhesion molecule, chemokine, and eicosanoid synthesis and by its antioxidant properties [18, 19]. Zadra et al. [10] showed which rosmarinic and chlorogenic acid found in the Solanum guaraniticum extract are related to antioxidant activity; it is known that vegetal extracts with these effects have been established as a therapeutic approach for treating inflammation [20]. The chlorogenic and gallic acid found in the $S$. paranense extract probably contributed to topical antiinflammatory activity, since another work from our research group [4] also found the same phenolic compounds in $S$. corymbiflorum extract which presented antiedematogenic and anti-inflammatory activities.

Research has shown that, besides polyphenols and flavonoids, alkaloids are often found in Solanum genus plants. Specifically, solanine was found in leaves of several species of this genus as S. alandiae, S. phureja spp., and S. sparsipilum, among others [21]. Moreover, the alkaloids possibly were also responsible for the anti-inflammatory activity of species of the Solanum genus $[4,22]$. This way, solanine almost certainly is related to a topical anti-inflammatory activity of the $S$. paranense alkaloid fraction and also may act synergistically with other compounds as rosmarinic acid and rutin present in the $S$. paranense crude extract.

Research by Kenny et al. [23] showed that Solanum tuberosum peel extract, glycoalkaloid, such as solanine, and $S$. tuberosum peel extracts enriched in glycoalkaloids have antiinflammatory activity in vitro. According to these authors, the aglycone unit of glycoalkaloids is essential for this effect 


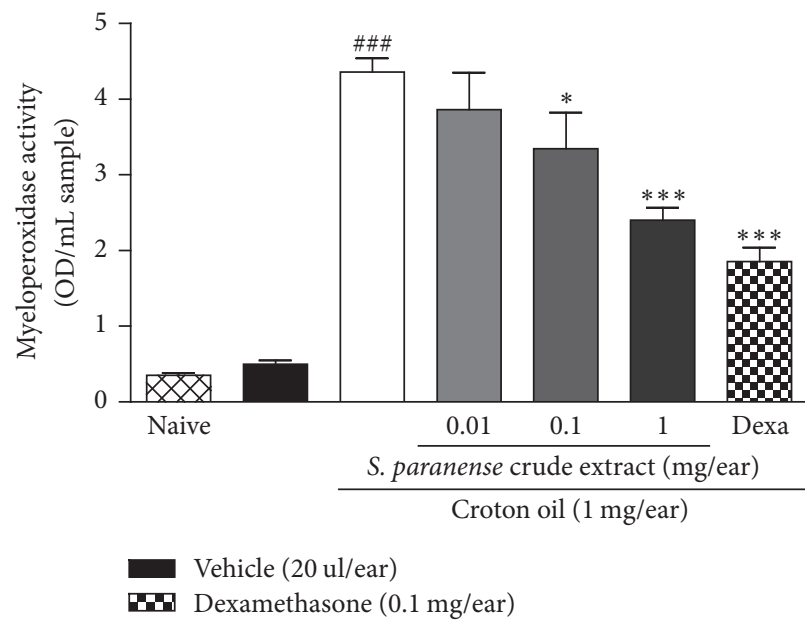

(a)

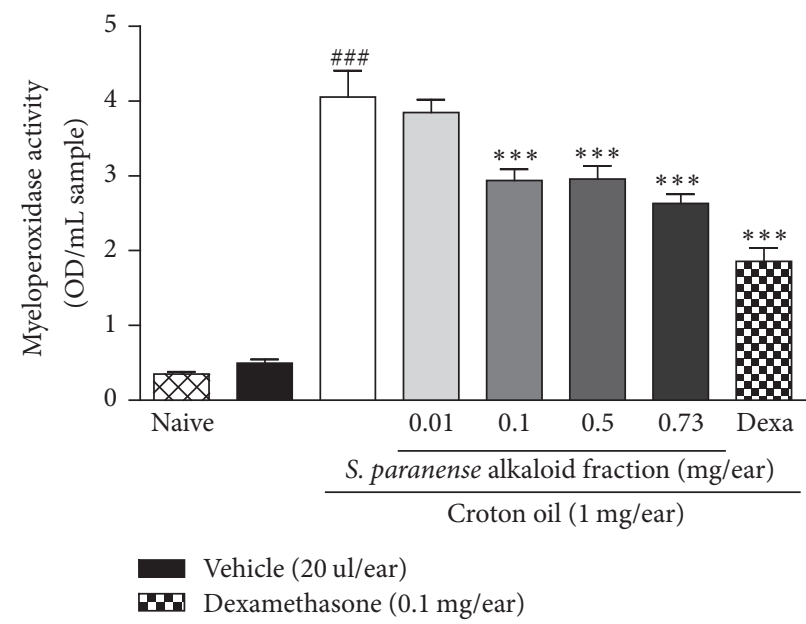

(b)

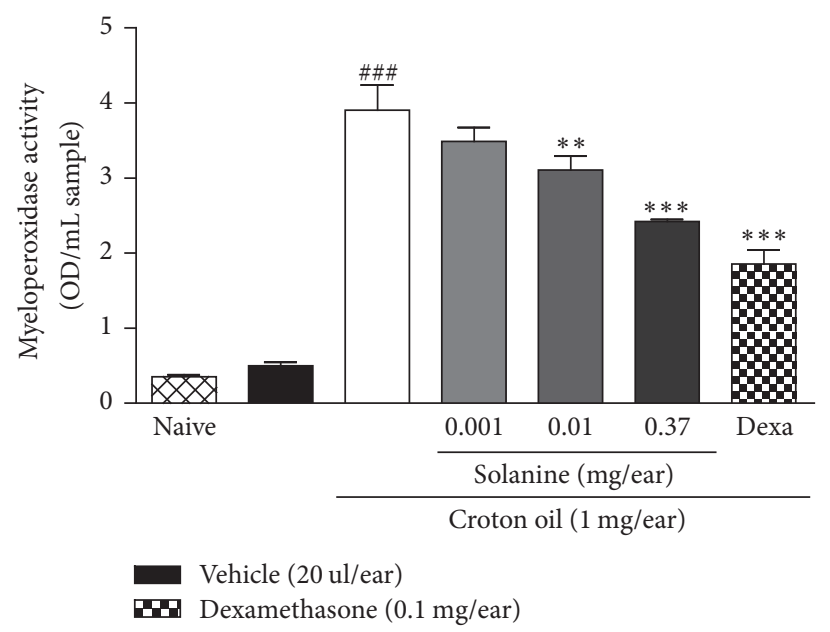

(c)

FIGURE 4: Effect of the S. paranense crude extract (a), S. paranense alkaloid fraction (b), solanine (c), and dexamethasone (Dexa) administered topically on MPO enzyme activity (OD/mL sample). Each bar represents the mean + SEM $(n=6) ;{ }^{\# \#} P<0.001$ when compared with the vehicle (acetone) and naïve groups. ${ }^{*} P<0.05,{ }^{* *} P<0.01$, and ${ }^{* * *} P<0.001$ when compared with the croton oil group (one-way ANOVA followed by post hoc Newman-Keuls test).

because these nitrogen compounds are analogs of steroids saponins such as diosgenin, a molecule with proven antiinflammatory activity.

\section{Conclusion}

In this research we confirmed for the first time that the extract and alkaloid fraction of $S$. paranense leaves possess antiedematogenic and anti-inflammatory activities in a croton oil-induced topical dermatitis model. These findings may be related with the solanine found in high quantity in the alkaloid fraction and also to a considerable quantity of phenolic compounds as rosmarinic acid and rutin present in the S. paranense extract.

\section{Conflicts of Interest}

The authors declare that there are no conflicts of interest regarding the publication of this paper.

\section{Authors' Contributions}

Mariana Piana, Camila Camponogara, and Sara Marchesan Oliveira participated in research design, conducted experiments, performed data analysis, and wrote or contributed to the writing of the manuscript. Mariana Piana and Aline Augusti Boligon were responsible for plant material and extractions, data analysis, and writing and discussion of these. All the authors reviewed the manuscript.

\section{Acknowledgments}

The authors would like to thank Margareth Linde Athayde for advice and Renato Zacchia for providing the identification of S. paranense. The authors acknowledge the financial support of CNPq/CAPES/FAPERGS (Process no. 16/2551-00002819) (Conselho Nacional de Desenvolvimento Cientifico e Tecnológico/Coordenação de Aperfeiçoamento de Pessoal 


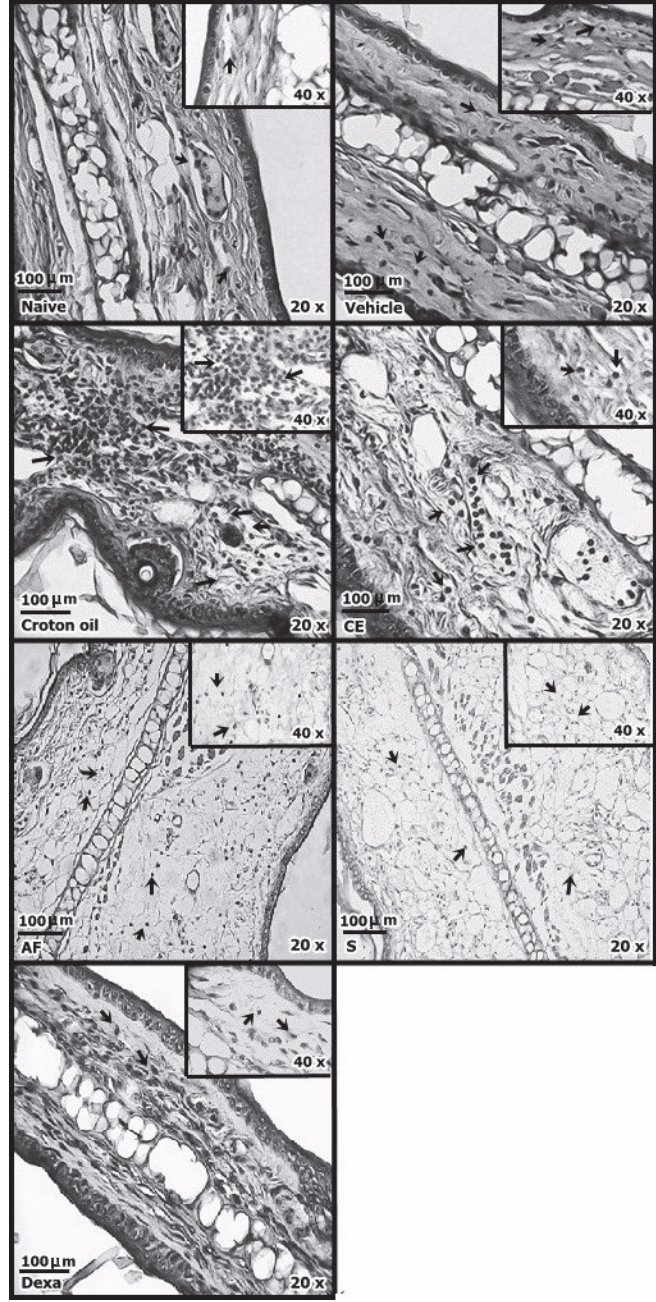

(a)

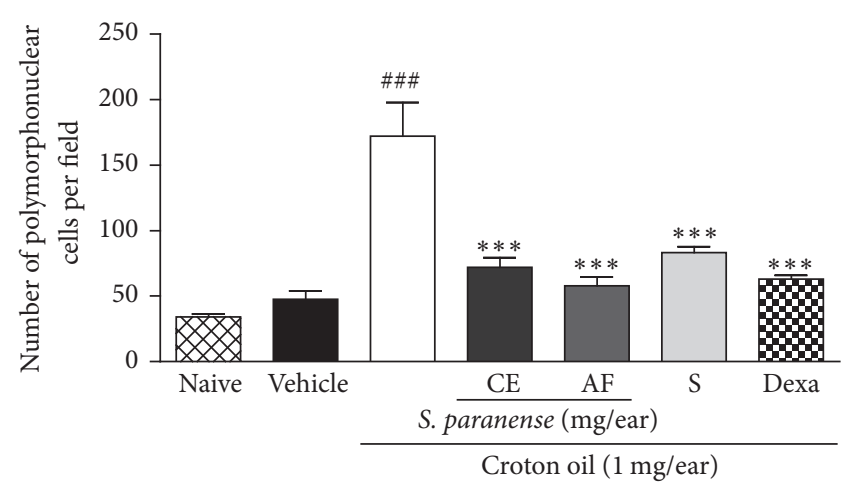

Hen

(b)

Figure 5: Effect of the $S$. paranense crude extract (CE; $1 \mathrm{mg} /$ ear), S. paranense alkaloid fraction (AF; $0.73 \mathrm{mg} / \mathrm{ear}$ ), solanine (S; $0.37 \mathrm{mg} / \mathrm{ear}$ ), and dexamethasone (Dexa) (0.1 mg/ear) on histological changes in the ears croton oil-treated mice. Representative pictures of histological sections from mice ears stained with hematoxylin-eosin (20 and 40x increments; scale $100 \mu \mathrm{m}$ ) (a) and counting polymorphonuclear cells per field (b) on acute skin inflammation model. The arrows (a) indicate polymorphonuclear leukocytes infiltration on the dermis. Each bar (b) represent the mean + SEM $(n=6) ;{ }^{\# \#} P<0.001$ when compared with the vehicle (acetone) and naïve groups. ${ }^{* *} P<0.01$ and ${ }^{* * *} P<0.001$ when compared with the croton oil group (one-way ANOVA followed by post hoc Newman-Keuls test).

de Nível Superior/Fundação de Amparo a Pesquisa do Rio Grande do Sul), Brazil. They also acknowledge fellowships from $\mathrm{CNPq}$ and CAPES.

\section{References}

[1] L. A. Chibli, K. C. M. Rodrigues, C. M. Gasparetto et al., "Antiinflammatory effects of Bryophyllum pinnatum (Lam.) Oken ethanol extract in acute and chronic cutaneous inflammation," Journal of Ethnopharmacology, vol. 154, no. 2, pp. 330-338, 2014.

[2] D. Y. Lee, B. K. Choo, T. Yoon et al., "Anti-inflammatory effects of Asparagus cochinchinensis extract in acute and chronic cutaneous inflammation," Journal of Ethnopharmacology, vol. 121, no. 1, pp. 28-34, 2009.

[3] M. C. Recio, I. Andújar, and J. L. Ríos, "Anti-inflammatory agents from plants: progress and potential," Current Medicinal Chemistry, vol. 19, no. 14, pp. 2088-2103, 2012.
[4] M. Piana, C. Camponogara, A. A. Boligon et al., "Topical anti-inflammatory activity of Solanum corymbiflorum leaves," Journal of Ethnopharmacology, vol. 179, pp. 16-21, 2016.

[5] H. Li, Z. Deng, R. Liu, S. Loewen, and R. Tsao, "Bioaccessibility, in vitro antioxidant activities and in vivo anti-inflammatory activities of a purple tomato (Solanum lycopersicum L.)," Food Chemistry, vol. 159, pp. 353-360, 2014.

[6] S. Emmanuel, S. Ignacimuthu, R. Perumalsamy, and T. Amalraj, "Antiinflammatory activity of Solanum trilobatum," Fitoterapia, vol. 77, no. 7-8, pp. 611-612, 2006.

[7] V. Elango, O. Carolin, and P. S. Raghu, "Anti-inflammatory activity of the flower extracts of Solanum nigrum in rats," Hygeia Journal for Drugs and Medicines, vol. 4, no. 1, pp. 59-62, 2012.

[8] D. Martins-Ramos, R. L. C. Bortoluzzi, and A. Mantovani, "Medicinal plants in a remnant of High Montane Araucaria Moist Forest, Urupema Municipality, Santa Catarina State, 
Brazil," Revista Brasileira de Plantas Medicinais, vol. 12, no. 3, pp. 380-397, 2010.

[9] A. Sotelo and B. Serrano, "High-performance liquid chromatographic determination of the glycoalkaloids $\alpha$-solanine and $\alpha$-chaconine in 12 commercial varieties of Mexican potato," Journal of Agricultural and Food Chemistry, vol. 48, no. 6, pp. 2472-2475, 2000.

[10] M. Zadra, M. Piana, T. F. De Brum et al., "Antioxidant activity and phytochemical composition of the leaves of solanum guaraniticum A. St.-Hil," Molecules, vol. 17, no. 11, pp. 1256012574, 2012.

[11] C. R. Silva, S. M. Oliveira, M. F. Rossato et al., "The involvement of TRPA1 channel activation in the inflammatory response evoked by topical application of cinnamaldehyde to mice," Life Sciences, vol. 88, no. 25-26, pp. 1077-1087, 2011.

[12] S. M. Oliveira, C. R. Silva, A. P. Wentz et al., "Antinociceptive effect of 3-(4-fluorophenyl)-5-trifluoromethyl-1H-1tosylpyrazole. A Celecoxib structural analog in models of pathological pain," Pharmacology Biochemistry and Behavior, vol. 124, pp. 396-404, 2014.

[13] C. G. De Vry, M. Valdez, M. Lazarov et al., “Topical application of a novel immunomodulatory peptide, RDP58, reduces skin inflammation in the phorbol ester-induced dermatitis model," Journal of Investigative Dermatology, vol. 125, no. 3, pp. 473-481, 2005.

[14] A. Cavender, "Folk medical uses of plant foods in southern Appalachia, United States," Journal of Ethnopharmacology, vol. 108, no. 1, pp. 74-84, 2006.

[15] M. I. Thabrew, M. G. Dharmasiri, and L. Senaratne, "Antiinflammatory and analgesic activity in the polyherbal formulation Maharasnadhi Quathar," Journal of Ethnopharmacology, vol. 85, no. 2-3, pp. 261-267, 2003.

[16] G. A. F. Da Costa, M. G. Morais, A. A. Saldanha et al., "Antioxidant, antibacterial, cytotoxic, and anti-inflammatory potential of the leaves of Solanum lycocarpum A. St. Hil. (Solanaceae)," Evidence-Based Complementary and Alternative Medicine, vol. 2015, Article ID 315987, 8 pages, 2015.

[17] M. Piana, M. A. Silva, G. Trevisan et al., "Antiinflammatory effects of Viola tricolor gel in a model of sunburn in rats and the gel stability study," Journal of Ethnopharmacology, vol. 150, no. 2, pp. 458-465, 2013.

[18] J. Rocha, M. Eduardo-Figueira, A. Barateiro et al., "Antiinflammatory effect of rosmarinic acid and an extract of rosmarinus officinalis in rat models of local and systemic inflammation," Basic and Clinical Pharmacology and Toxicology, vol. 116, no. 5, pp. 398-413, 2015.

[19] N. Osakabe, H. Takano, C. Sanbongi et al., "Anti-inflammatory and anti-allergic effect of rosmarinic acid (RA); inhibition of seasonal allergic rhinoconjunctivitis (SAR) and its mechanism," BioFactors, vol. 21, no. 1-4, pp. 127-131, 2004.

[20] R. J. Nijveldt, E. V. Nood, D. E. V. Hoorn, P. G. Boelens, K. V. Norren, and P. A. V. Leeuwen, "Flavonoids: a review of probable mechanisms of action and potential applications," The American Journal of Clinical Nutrition, vol. 74, no. 4, pp. 418-425, 2001.

[21] M. Distl and M. Wink, "Identification and quantification of steroidal alkaloids from wild tuber-bearing solanum species by HPLC and LC-ESI-MS," Potato Research, vol. 52, no. 1, pp. 79104, 2009.

[22] O. M. Aboyade, D. S. Grierson, and A. J. Afolayan, "Comparative studies on the anti-inflammatory and analgesic activity of the aqueous extracts from fresh, dried and boiled berries of solanum aculeastrum dunal," African Journal of Biotechnology, vol. 9, no. 20, pp. 3011-3015, 2010.

[23] O. M. Kenny, C. M. McCarthy, N. P. Brunton et al., "Antiinflammatory properties of potato glycoalkaloids in stimulated Jurkat and Raw 264.7 mouse macrophages," Life Sciences, vol. 92, no. 13, pp. 775-782, 2013. 


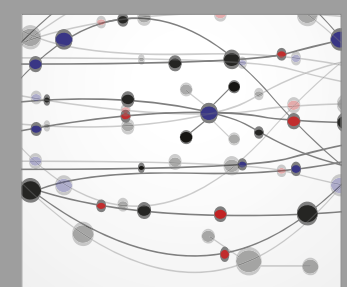

The Scientific World Journal
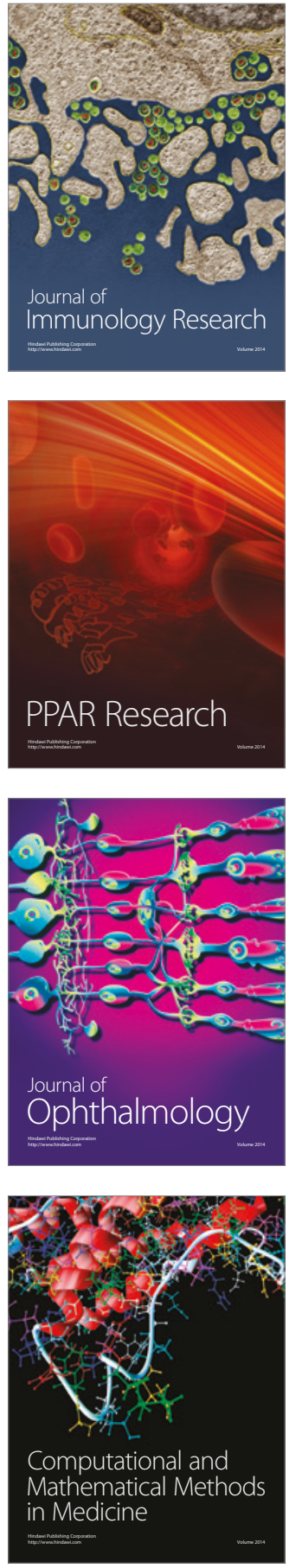

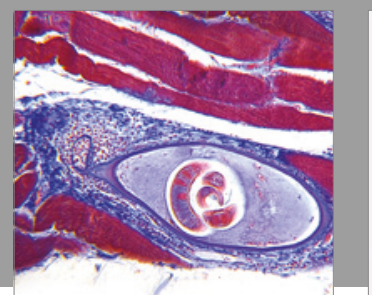

Gastroenterology Research and Practice
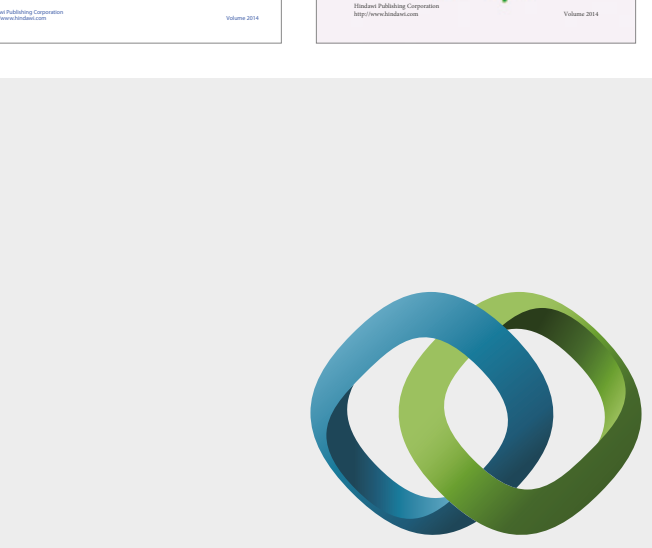

\section{Hindawi}

Submit your manuscripts at

https://www.hindawi.com
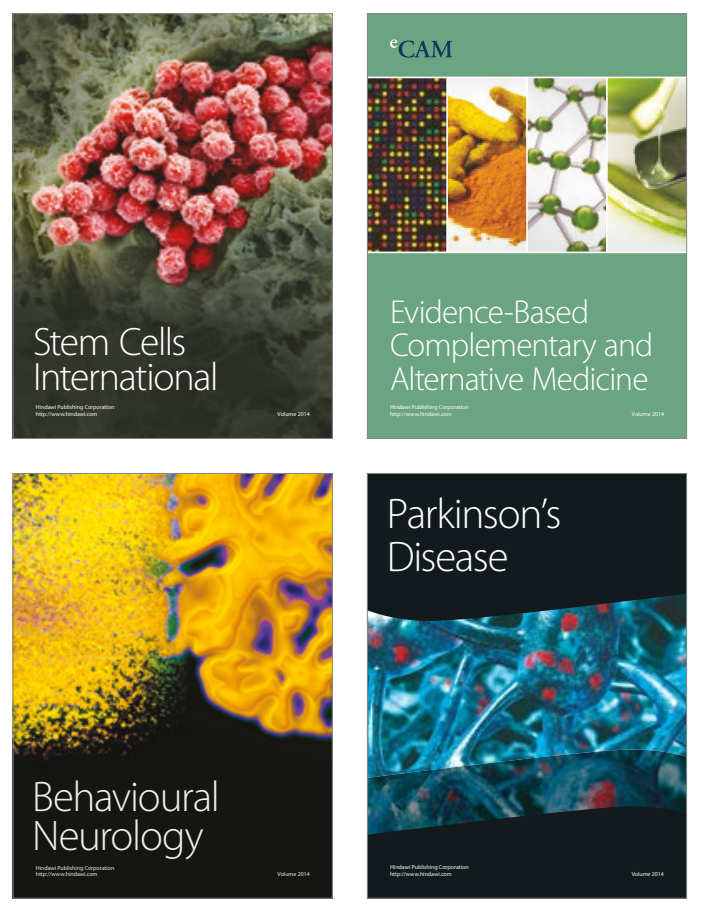
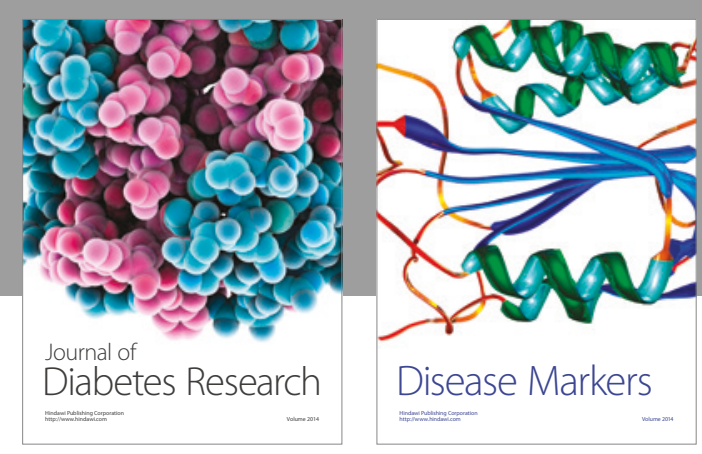

Disease Markers
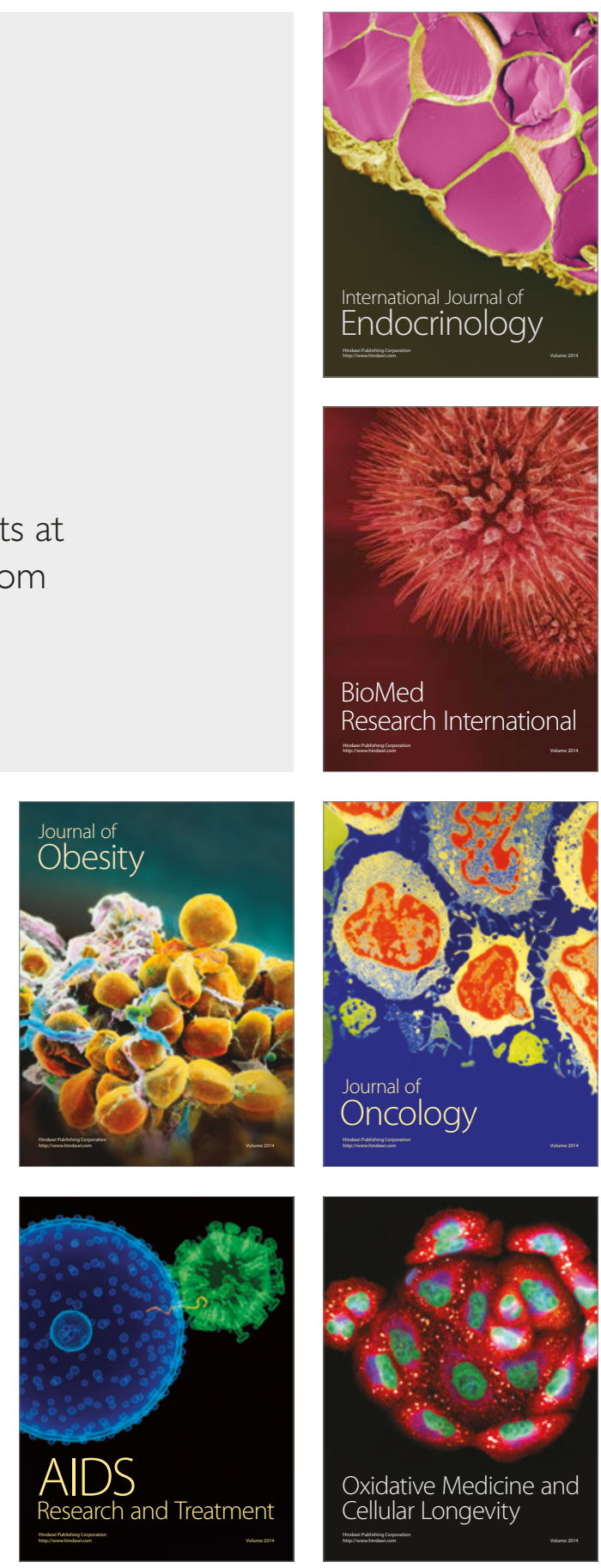